\title{
Career exploration behavior of Korean medical students
}

Hyejin $\mathrm{An}^{1}$ and Seung-Hee $\mathrm{Lee}^{2}$

${ }^{1}$ Department of Early Childhood Education, Suwon Women's University, Suwon, and ${ }^{2}$ Department of Medical Education, Seoul National University College of Medicine, Seoul, Korea

Purpose: This study is to analyze the effects of medical students' social support and career barriers on career exploration behavior mediated by career decision-making self-efficacy.

Methods: We applied the t-test to investigate the difference among the variables based on gender and admission types. Also, we performed path analysis to verify the effect of perceived career barriers and social support on career exploration behavior with career decision efficacy as a mediator.

Results: First, we noted statistically significant gender and admission type difference in social support, career barriers and career exploration behaviors. Second, social support and career barriers were found to influence career exploration behavior as a mediating variable for career decision-making self-efficacy.

Conclusion: Social support and career barriers as perceived by medical students influenced their career exploration behavior, with their decision-making self-efficacy serving as a full mediator. Therefore, this study has educational implications for career program development and educational training for career decision-making self-efficacy.

Key Words: Social support, Career barriers, Career decision-making self-efficacy, Career exploration behavior

\section{Introduction}

Exploring and choosing the right career is one of the most important developmental steps. The exploratory stage is a critical career exploration period when adolescents and college students find their own capabilities and interests, set a career goal, and engage in specific career planning [1]. However, many adolescents delay their career development and think about their career only after they attend university.

Park et al. [2] surveyed 1,221 Korean medical students about their thoughts on their career and found that 57\% of the students in fourth year were seriously concerned about their career after graduation, while 30\% said that they did not have an aptitude for medicine. Besides, approximately $17 \%$ of those who experienced academic failure or took a leave of absence responded that it was due to a discord between their aptitude and medical study [3].

Recent career theories have emphasized the influence of environmental factors, and trials have been conducted to explain the interaction between individual career development factors and environmental contexts using
Received: February 17, 2017 • Revised: May 3, 2017 • Accepted: July 24, 2017 Corresponding Author: Seung-Hee Lee (https://orcid.org/0000-0001-8672-5253) Department of Medical Education, Seoul National University College of Medicine, 103 Daehak-ro, Jongno-gu, Seoul 03080, Korea

Tel: +82.2.740.8406 Fax:+82.2.741.1186 email: 1shcho@snu.ac.kr
Korean J Med Educ 2017 Sep; 29(3): 175-185.

https://doi.org/10.3946/kjme.2017.63

eISSN: 2005-7288

(C) The Korean Society of Medical Education. All rights reserved. This is an open-access article distributed under the terms of the Creative Commons Attribution Non-Commercial License (http:// creativecommons.org/licenses/by-nc/3.0/), which permits unrestricted non-commercial use, distribution, and reproduction in any medium, provided the original work is properly cited. 
the Social Cognitive Career Theory (SCCT). This theory, based on Bandura [4]'s social cognitive theory, explains a range of variables affecting career development, with the perspective that personal beliefs about one's capability to plan and perform tasks in the course of career development are important. Career decision efficacy, meaning how confident an individual is about his/her success in performing a given task, is important for that individual to begin and continue a career-related task.

SCCT also states that diverse social and cultural factors in addition to individual cognition, competency, and interests influence personal career development and career choice. In particular, career barriers and social support are contextual variables that affect an individual's career decisions, and provide a framework to understand the process of establishing a career goal or switching to career preparation depending on how the two variables are perceived [5].

In the face of a changing occupational world, it is critical for college students to explore a career for which they have an aptitude. Career exploration behavior refers to cognitive and behavioral activities to access related information to understand oneself and the working world to make a career decision or for career development. This behavior occurs during an individual's entire life and most frequently when college students have to decide one's career after graduation [6].

Many college students have to overcome numerous obstacles when exploring career. Swanson et al. [7] identified the factors that interrupt progress in planning an occupation or career as career barriers, these were defined as internal or environmental events or conditions that slow career progression [8], past troubles and future challenges for a career plan or goal [9].

According to the career choice model that emphasizes the environmental impacts, different environments provide different learning opportunities and resources, and the different learning opportunities lead different beliefs. Students have different expectations of the consequence of their behavior depending on these beliefs, thus resulting in different career choices. In this process, contextual factors (social support or career barriers) may limit or expand individuals' career choices. That is, people who frequently perceive career barriers find career development difficult, while those who perceive a great deal of support-e.g., teachers or parents - have a high level of career planning and feel that career development or career decision-making is easy $[10,11]$.

SCCT explains that career decision efficacy is an important variable in the course of identifying the effect of career barriers and social support on career development. It was found that social support for university students making their career decision had a direct and positive effect on career exploration behavior, and career decision efficacy had a mediating effect on the relationship between parents and career exploration behavior [12].

Many studies have were SCCT perspective to adolescents and university students to verify the structural model of career exploration behavior [5,10,12]. However, it was hard to understand the career development model as it relates to medical students, as few studies have sampled them. Kwon [13] suggested that personal variables like gender, age, and education should be taken into account carefully to understand the career development model since these contextual variables exert a significant influence on career exploration and career decision-making in practice.

Member countries of the Organisation for Economic Cooperation and Development highlight the importance of a career guidance program that systemically supports students to perceive, explore, and prepare for careers in the transition from education to professional jobs. 
Universities have reform their career guidance organizations under different names to offer support services to students on careers and employment. Despite such efforts, neither a career guidance program appropriate for the curriculum of medical schools nor a career counseling program specifically designed for medical students exists. Furthermore, medical students have limited time to explore careers and find career opportunities in different fields because of heavy workloads and frequent assessments, and medical schools also find it difficult to operate a systemic career guidance course and program [14].

The present study examined the characteristics of social support, career barriers, career decision efficacy, and career exploration behavior depending on gender and admission types of medical students to understand their career development. By applying the SCCT model, this study verified the structural relationship between career barriers/social support and career exploration behavior with career decision efficacy as a mediator. The following two research questions were addressed: (1) Research question 1: Do career barriers, social support, career decision efficacy, and career exploration behavior differ depending on a students' gender and admission status? (2) Research question 2: How do career barriers and social support, with career decision efficacy as a mediator, affect the career exploration behavior of medical students?

\section{Methods}

\section{Participants}

The study surveyed 285 undergraduates and graduate students at the Seoul National University College of Medicine. The students at the College of Medicine consist of those admitted by a college admission application process, transfer students with different majors, and students admitted via the graduate school admission process.

With the same curriculum for the undergraduates and graduate students, this medical school begins major classes from the first year and teaches clinical practices up to the third year. Accordingly, the period from the first to third years of medical school is important for career exploration, such as finding an aptitude for medical school and deciding on a major. There were 143 first-year students, 77 second-year students, and 65 third-year students, of whom 192 were men and 93 were women, and of whom 169 were undergraduates and 116 were transfer and graduate students based on their admission status.

\section{Survey instruments}

Medical students' career barriers, social support, career decision efficacy, and career exploration behavior were measured. The Korean Career Barrier Inventory (KCBI) developed by Kim [9] was employed to measure perceived career barriers. The KCBI consists of 45 items divided into nine subscales, with higher scores on a 4-point Likert scale indicating more perceived career barriers for each subscale.

Career indecisiveness (CI) as a sub-factor of career barrier means a lack of confidence in one's ability and determination. Interpersonal relationship (IR) refers to a tendency to perceive a lack of relational skills including social skills and sociality, which are required for IRs. Lack of vocational information (LV) means a lack of knowledge and career information in the process of making a career decision. Pressure from significant others (PS) means suffering from opposition and intervention by parents and friends in pursuing one's career. Lack of interest (LI) means not recognizing one's 
own area of interest. Future anxiety (FA) means a high level of worry and anxiety regarding one's career. Physical health $(\mathrm{PH})$ indicates when one perceives that one's health and physical strength are not sufficient for selecting and/or pursuing a career. Age-related problem (AR) means difficulties due to being too old or too young. Financial problems (FP) refer to financial difficulties in selecting a career or pursuing a career path [9].

In this study, reliability coefficients (i.e., Cronbach's a) for career barriers were estimated to be 0.83 for CI, 0.83 for IR, 0.81 for LV, 0.74 for PS, 0.70 for LI, 0.80 for $\mathrm{FA}, 0.88$ for $\mathrm{PH}, 0.90$ for $\mathrm{AR}$, and 0.82 for FP. Cronbach's $\alpha$ for this scale was 0.95 .

The revised social support scale was used to measure perceived social support [15]. The social support scale is comprises 22 items with four subscales. Subscales of social support include emotional support, which measures the extent to which basic desires are met through consideration and understanding; appraisal support, which means degree of evaluation and compliment from significant others; material support, the degree to which monetary or physical support is provided, or possibilities for such support; and information support, meaning support from one's surroundings when one makes decisions and solves problems. The above subscales were measured using 4-point Likert scales. The Cronbach's $\alpha$ for each subscale was $0.82,0.88,0.82$, and 0.88 , respectively. Cronbach's $\alpha$ for this scale was 0.95 .

The Career Decision-Making Self-Efficacy Scale was applied to measure perceived career decision efficacy [12]. The Korean Career Decision-Making Self-Efficacy Scale has 25 items with four subscales. As a subscale of the Career Decision-Making Self-Efficacy Scale, goal selection indicates whether one can make the appropriate decisions regarding one's career. Occupational information is a measurement of the ability to collect relevant and specific information on an occupation of interest. Problem-solving measures the ability to solve problems and deal with difficulties related to a career. Planning means whether one can design specific action plans to pursue career goals. The above were measured on 6-point Likert scales. The Cronbach's $\alpha$ for each was 0.89, 0.87, 0.89, and 0.77, respectively. Cronbach's $\alpha$ for this scale was 0.93 .

The Career Exploration Behavior Inventory was employed to measure the perceived career exploration behavior of the medical students [16]. The Career Exploration Behavior Inventory consists of 16 items divided into three subscales. Information gathering as a subscale of career exploration behavior means collecting information to understand oneself and one's own field of work. Tool seeking activity comprises collecting information and tools required for one's career goal. Practical effort is the act of investing time and effort toward a set a career goal. The above were measured with 4-point Likert scales. The Cronbach's $\alpha$ for each was $0.73,0.83$, and 0.77 , respectively. Cronbach's $\alpha$ for this scale was 0.91 .

\section{Data analysis}

We used IBM SPSS ver. 20.0 (IBM Corp., Armonk, USA) and AMOS ver. 20.0 (IBM Corp.) to verify the effect of the perceived career barriers and social support of the medical students on career exploration behavior, with career decision efficacy as a mediator. Correlation analysis was used to identify the relations among variables, the $\mathrm{t}$-test was used to investigate the difference among the variables based on gender and admission status, and the Cronbach $\alpha$ coefficient was used to confirm the reliability of each item. We also performed path analysis to verify the effect of perceived career barriers and social support on career exploration behavior, with career decision efficacy as a mediator. The Sobel test was used to verify whether career 
decision efficacy is statistically significant as a mediating variable.

\section{Results}

\section{Differences in career barriers, social sup- port, career decision efficacy, and career exploration behavior based on gender and admission status of the medical students}

The $\mathrm{t}$-test was used to analyze differences in career barriers/social support, career decision efficacy, and career exploration behavior based the personal factors of the medical students. Differences in career barriers/ social support, career decision efficacy, and career exploration behavior based on gender were statistically significant for all subscales of emotional, evaluative, material, and informational support under the social support category (Table 1), indicating that females perceived social support more than males.

On the other hand, males perceived more career barriers than females in all subscales, except the subscale PS. The males and females were significantly different, particularly in the subscales of LI, FP, and AR. Gender difference was not measured for career decision efficacy. Males showed higher career decision efficacy in all the subscales, except for the goal selection. Males recorded higher scores on the information-gathering, toolseeking activity, and practical effort under the career

Table 1. Gender Differences in Perceived Social Support, Career Barriers, Career Decision-Making Self-Efficacy, and Career Exploration Behavior

\begin{tabular}{lccc}
\multicolumn{1}{c}{ Variable (scale) } & Male $(\mathrm{n}=192)$ & Female $(\mathrm{n}=93)$ & $\mathrm{t}$-value \\
\hline Social support (4-point) & & & \\
Emotional support & $3.25 \pm 0.44$ & $3.44 \pm 0.48$ & $3.30^{* *}$ \\
Appraisal support & $3.31 \pm 0.46$ & $3.50 \pm 0.46$ & $3.27^{* *}$ \\
Material support & $2.98 \pm 0.48$ & $3.20 \pm 0.49$ & $3.64^{* * *}$ \\
Informative support & $3.22 \pm 0.46$ & $3.36 \pm 0.49$ & $2.33^{*}$ \\
Career barriers (4-point) & & & \\
Career indecisiveness & $2.13 \pm 0.52$ & $2.12 \pm 0.52$ & 0.16 \\
Interpersonal relationship & $2.00 \pm 0.62$ & $1.93 \pm 0.52$ & 0.98 \\
Pressure from significant others & $1.93 \pm 0.51$ & $1.95 \pm 0.49$ & 0.40 \\
Lack of vocational information & $2.31 \pm 0.61$ & $2.28 \pm 0.55$ & 0.44 \\
Lack of interest & $2.14 \pm 0.48$ & $2.03 \pm 0.41$ & $2.00^{*}$ \\
Future anxiety & $2.18 \pm 0.54$ & $2.15 \pm 0.49$ & 0.48 \\
Financial problem & $1.96 \pm 0.57$ & $1.81 \pm 0.53$ & $2.15^{*}$ \\
Physical health & $1.63 \pm 0.56$ & $1.59 \pm 0.54$ & 0.59 \\
Age-related problem & $1.65 \pm 0.65$ & $1.50 \pm 0.57$ & $2.01^{*}$ \\
Career decision-making self-efficacy (6-point) & & & \\
Goal selection & $4.43 \pm 0.65$ & $4.48 \pm 0.67$ & 0.65 \\
Occupational information & $4.02 \pm 0.88$ & $3.96 \pm 0.77$ & 0.61 \\
Problem-solving & $4.21 \pm 0.93$ & $4.19 \pm 0.90$ & 0.16 \\
Planning & $3.86 \pm 0.80$ & $3.77 \pm 0.67$ & 0.92 \\
Career exploration behavior (4-point) & & & \\
Information-gathering & $2.18 \pm 0.60$ & $2.12 \pm 0.58$ & 0.79 \\
Tool-seeking activity & $2.05 \pm 0.60$ & $2.05 \pm 0.63$ & 0.05 \\
Practical effort & $2.06 \pm 0.64$ & $1.90 \pm 0.54$ & $2.10^{*}$ \\
\hline
\end{tabular}

Data are presented as mean \pm standard deviation. ${ }^{*} \mathrm{p}<0.05,{ }^{* *} \mathrm{p}<0.01,{ }^{* * *} \mathrm{p}<0.001$. 
exploration behavior category than the females, with the practical effort suggesting particularly significant gender difference.

The study examined the differences in career barriers/ social support, career decision efficacy, and career exploration behavior based on different admission status: undergraduates and transferred students from other medical schools/graduate students (Table 2). Social support depending on the admission status was significantly different in all subscales under this category, indicating that the transferred and graduate students perceived greater emotional, evaluative, material, and informational support than the undergraduates.
The participating groups from the two different admission statuses showed statistically significant differences in all the subscales of career barriers except for PS and AR. The undergraduates perceived more career barriers in designing their career than the transferred and graduate students. Besides, the transferred and graduate students recorded significantly higher scores than the undergraduates in all the subscales of career decision efficacy. This suggests that the transferred and graduate students have stronger beliefs than the undergraduates in career choice and career decision. The information-gathering and tool-seeking activity under the career exploration behavior category was also

Table 2. Difference in Social Support, Career Barriers, Career Decision-Making Self-Efficacy, and Career Exploration Behavior According to Student Admission Status

\begin{tabular}{lccc}
\hline \multicolumn{1}{c}{ Variable (scale) } & UMS $(\mathrm{n}=169)$ & GMSS/TMS $(\mathrm{n}=116)$ & t-value \\
\hline Social support (4-point) & & & \\
Emotional support & $3.26 \pm 0.44$ & $3.39 \pm 0.49$ & $2.29^{*}$ \\
Appraisal support & $3.30 \pm 0.45$ & $3.48 \pm 0.48$ & $3.10^{* *}$ \\
Material support & $3.00 \pm 0.50$ & $3.13 \pm 0.49$ & $2.21^{*}$ \\
Informative support & $3.22 \pm 0.44$ & $3.34 \pm 0.51$ & $2.06^{*}$ \\
Career barriers (4-point) & & & \\
Career indecisiveness & $2.23 \pm 0.49$ & $1.99 \pm 0.53$ & $3.94^{* * *}$ \\
Interpersonal relationship & $2.06 \pm 0.58$ & $1.88 \pm 0.59$ & $2.47^{*}$ \\
Pressure from significant others & $1.98 \pm 0.49$ & $1.87 \pm 0.51$ & 1.82 \\
Lack of vocational information & $2.41 \pm 0.56$ & $2.14 \pm 0.61$ & $3.75^{* * *}$ \\
Lack of interest & $2.17 \pm 0.45$ & $2.02 \pm 0.47$ & $2.68^{* *}$ \\
Future anxiety & $2.25 \pm 0.53$ & $2.06 \pm 0.51$ & $2.90^{* *}$ \\
Financial problem & $1.97 \pm 0.56$ & $1.83 \pm 0.55$ & $2.09^{*}$ \\
Physical health & $1.68 \pm 0.56$ & $1.53 \pm 0.53$ & $2.22^{*}$ \\
Age-related problem & $1.55 \pm 0.58$ & $1.67 \pm 0.68$ & 1.59 \\
Career decision-making self-efficacy (6-point) & & & \\
Goal selection & $4.29 \pm 0.63$ & $4.69 \pm 0.63$ & $5.26^{* * *}$ \\
Occupational information & $3.86 \pm 0.81$ & $4.21 \pm 0.86$ & $3.52^{* *}$ \\
Problem-solving & $4.07 \pm 0.87$ & $4.41 \pm 0.96$ & $3.12^{* *}$ \\
Planning & $3.65 \pm 0.66$ & $4.11 \pm 0.81$ & $5.30^{* * *}$ \\
Career exploration behavior (4-point) & & & \\
Information-gathering & $2.08 \pm 0.56$ & $2.27 \pm 0.62$ & $2.60^{*}$ \\
Tool-seeking activity & $1.96 \pm 0.57$ & $2.18 \pm 0.64$ & $3.03^{* *}$ \\
Practical effort & $1.96 \pm 0.60$ & $2.08 \pm 0.63$ & 1.69 \\
\hline
\end{tabular}

Data are presented as mean \pm standard deviation.

UMS: Undergraduate medical student, GMSS: Graduate medical school student, TMS: Transferred medical student. ${ }^{*} \mathrm{p}<0.05$, ${ }^{* *} \mathrm{p}<0.01$, ${ }^{* *} \mathrm{p}<0.001$. 
statistically significant difference, suggesting that graduate medical school student and transferred medical student pursue career exploration behavior more actively than undergraduate medical student.

\section{Relationships of career barriers, social support, career decision efficacy, and career exploration behavior}

The study analyzed the correlation among the variables to verify the structural relationship of career barriers, social support, career decision efficacy, and career exploration behavior. For a basic analysis of the relational model among career barrier, social support, career decision efficacy, and career exploration behaviors, correlations were analyzed. Correlations allow examination of multicollinearity, which makes it difficult to distinguish effects on dependent variables due to high correlations among independent variables. It examined the variance inflation factor (VIF) and tolerance to confirm multicollinearity among the variables, and subsequently found that multicollinearity did not occur with all the VIFs 10 or lower and all tolerance 0.1 and higher [17].

All the subscales of social support and career barriers subscales were significantly negative correlations at -0.14 to 0.39 except for the material support of the former and AR of the latter. The subscales of social support and career decision efficacy presented significantly positive correlations at 0.21 to 0.33 . Meanwhile, all the subscales of career barriers, except for the AR and those of career decision efficacy, demonstrated significantly negative correlations at -0.14 to -0.67 . In particular, the CI of career barrier, the goal selection, and planning of career decision efficacy recorded a very negative correlation of -0.52 while the $\mathrm{LV}$ of the former and planning of the latter showed -0.53 . However, the subscales of career decision efficacy and career exploration behavior presented positive correlations of 0.18 to 0.46

\section{Mediating effect of career decision efficacy on the relationship among social support, career barrier, and career exploration behavior}

The study established a full mediation model and partial mediation model to verify the mediating effect of career decision efficacy on relationship among social support, career barrier, and career exploration behavior. The full mediation model has mediation variables between the independent variables and the dependent variables. Without such mediating variable, the independent variables cannot affect the dependent variables. As for the partial mediation model, regardless of the mediation variables, the independent variables can affect the dependent variables $[17,18]$. To decide which model is more appropriate, goodness-of-fit (GOF) was compared. The results of comparing the GOFs of the two models showed that the full mediation model (comparative fit index $[\mathrm{CFI}]=0.910$, Tucker-Lewis index $[\mathrm{TLI}]=0.875$, root mean square error of approximation [RMSEA] $=0.085$ ) has a better GOF than the partial mediation model (CFI=0.909, TLI $=0.873$, RMSEA $=0.085$ ).

There are various GOF indices that show the fitness of a model. However, CFI, TLI, and RMSEA are frequently used because the $\chi^{2}$ value is sensitive to model error and sample size. The fit is good when the CFI and TLI are 0.9 and higher, and the RMSEA is 0.05 and below. The fit is acceptable when the RMSEA is between 0.08 and 0.10 , but bad when it is above $0.10[17,18]$. The complete mediation model of this study had a generally satisfactory fit. However, Hong [18] explained that the TLI may not be high when the model is complicated no matter how well it describes the data.

The path diagrams of the two models showed that 
social support and career barriers in the partial mediation model had an insignificant path for career exploration behavior (Figs 1, 2). This suggested the validity of the full mediation model under which social support and career barriers affect career exploration behavior, with career decision efficacy as a mediator. The path coefficient and path diagram of the full mediation model illustrated that career barriers had a negative influence on career decision efficacy $(\beta=-0.53, p<0.001)$ (Fig. 1), social support had a positive influence on career decision efficacy $(\beta=0.18, p<0.01)$, and career decision efficacy had a positive influence on career exploration behavior $(\beta=0.47, \mathrm{p}<0.001)$. Additionally, career barriers and social support were a negatively correlated $(r=-0.43$, $\mathrm{p}<0.001)$. In other words, the full mediation model was verified where career barriers and social support affect career decision efficacy, and career decision efficacy influences career exploration behavior.
Following this, the study verified the mediating effect of career decision efficacy on career barrier, social support, and career exploration behavior using the Z-test proposed by Sobel [19].

$$
Z_{a b}=\frac{a b}{\sqrt{b^{2} S E_{a}^{2}+a^{2} S E_{b}^{2}}}
$$

The null hypothesis is rejected when the Z-value of this test is greater than 1.96 or smaller than -1.96 . Fig. 1 shows that the Z-score of career exploration behavior for the mediating effect of career decision efficacy on career barriers is $-4.99(\mathrm{p}<0.001)$, and that the Z-score of career exploration behavior for the mediating effect of career decision efficacy on social support is 2.56 $(p<0.05)$. According to the verification results, both career barriers and social support with career decision efficacy as a mediator were statistically significant for all path coefficients of career exploration behavior. This

Fig. 1. Full Mediation Model of Career Exploration Behavior

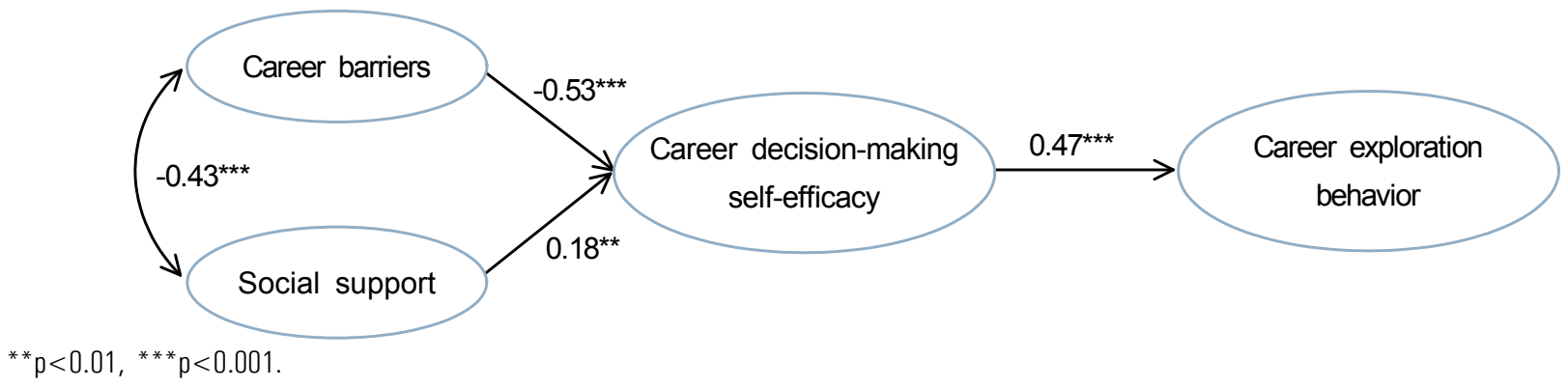

Fig. 2. Partial Mediation Model of Career Exploration Behavior

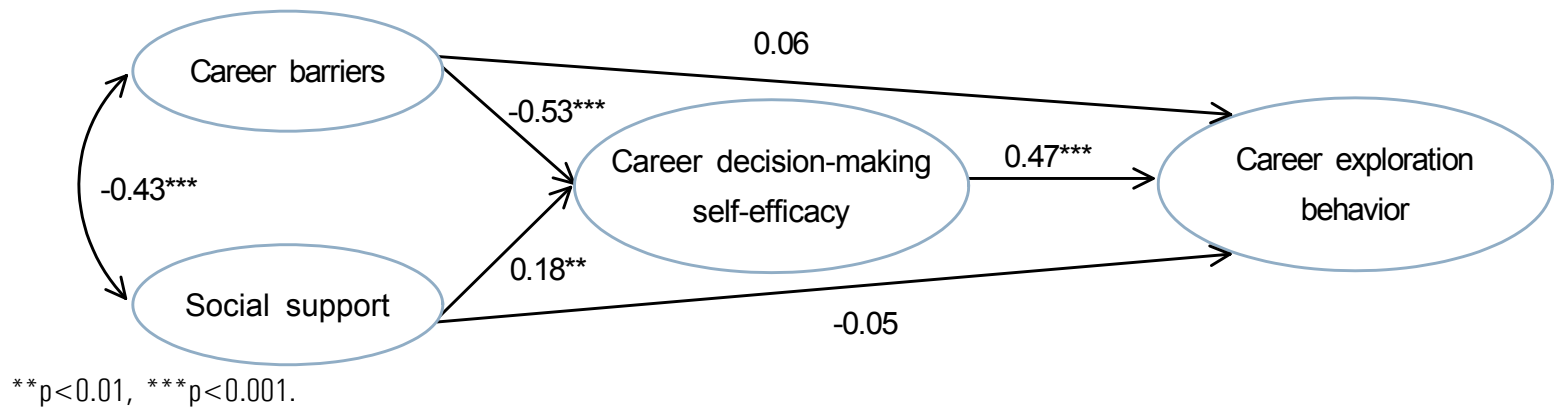


meant that career decision efficacy served as a mediating factor for relationship of career barrier, social support, and career exploration behavior.

\section{Discussion}

The differences in perceived career barriers, social support, career decision efficacy, and career exploration behavior based on gender and students' admission status showed that the female students perceived that they obtained significantly more social supports than the male students. On the other hand, the male students perceived significantly more career barriers in the subscales of the $\mathrm{LI}, \mathrm{FP}$, and AR, and they engaged in career exploration behavior than the female. These are consistent with You and Yoon [20], who analyzed gender differences among college students and university students in social support, career barrier, and career preparation behavior and showed that male students had significantly higher scores in career barriers and career preparation behavior than female students. Identifying gender gaps in variables of Korean medical students' career development suggests the necessity of career consultation and educational measures depending on gender and could be utilized to develop specific career programs by gender.

We also analyzed the differences in social support, career barrier, career decision efficacy, and career exploration behavior of the undergraduates and transferred and graduate students We found that the transferred and graduate students obtained significantly more social support than the undergraduates and had significantly higher scores in career decision efficacy and career exploration behavior. The result was generally consistent with that of Son and Son [21], who examined career decision efficacy and career exploration behavior of students in each school year and found that the scores for the two categories increased as the students advanced through school, and high scores were presented in career decision efficacy and career preparation behavior. Besides, the undergraduates felt more career barriers than the transferred and graduate students in all the subscales, except for the PS and AR.

This implies that the graduates and transferred students prepare for career plan more actively than undergraduates, as they are relatively older, have more experiences in career exploration throughout their undergraduate studies, and have more passion for and attachment to academic achievement and career decision because they made a belated choice to study medicine. Therefore, a curriculum and career program should be developed that can help the medical students in the undergraduate course explore their career and enhance their ability to design a specific career.

The structural relationship between perceived career barriers/social support and career exploration behavior, with career decision efficacy as a mediator, showed that the full mediation model was valid under which career barriers and social support had a statistically significant effect on career decision efficacy, while career decision efficacy had a statistically significant effect on career exploration behavior. The result is somewhat inconsistent with You and Yoon [20], describing that university students' career barriers and social support had a partial mediating effect on career exploration behavior, with career efficacy as a mediator. However, it was consistent with that of Oh [22] showing a full mediating effect of career decision efficacy on the relationship between career barriers perceived by university students and career exploration behavior.

The study is meaningful as it verified the structural relationship of career barriers and social support perceived by the medical students and career exploration behavior with career decision efficacy as a mediator to 
understand the career development model of medical schools by applying the SCCT. Although universities implement career programs by reforming their career guidance organizations of various names, they are inappropriate for medical students because of their busy academic schedule and the program contents. Therefore, studies on the variables that affect the career exploration behavior of medical students are important to help understand the career characteristics of medical students, provide career counseling for them, develop career guidance programs for medical schools, and apply the developed programs to education.

Our suggestions for further studies are as follows. First, it would be unreasonable to apply the study result to all medical schools since the medical students of only one university were involved in the study. Career development differences as well as variables that affect the career exploration behavior of the undergraduates or graduate students from more medical schools need to be studied. Second, the study chose only career barriers, social support, and career decision efficacy as the variables that affect the career exploration behavior of the medical students by applying the SCCT. Further studies are required to consider more personal and contextual variables that influence career exploration behavior to explain medical students' career development.

\section{ORCID:}

Hyejin An: https://orcid.org/0000-0003-3461-2702;

Seung-Hee Lee: https://orcid.org/0000-0001-8672-5253

Acknowledgements: None.

Funding: None.

Conflicts of interest: None.

Author contributions: All authors had full access to all of the data in the study and take responsibility for the integrity of the data and the accuracy of the data analysis. Concept and design: all authors; Data collection: all authors; Statistical analysis and interpretation: HJA; Drafting of the manuscript: all authors; Critical revision of the manuscript for important intellectual content: all authors; Final approval of the version: all authors.

\section{References}

1. Super DE. A life-span, life-space approach to career development. J Vocat Behav. 1980;16(3):282-298.

2. Park JH, Kim KH, Jun HR, Lee JY. A national sample survey of medical students about their perception and evaluation on medical study, career plan, and medical care system: part 1 . survey methods and characteristics of sample. Korean J Med Educ. 1999;11(2):339-363.

3. Han ER, Chung EK, Oh SA, Chay KO, Woo YJ. Medical students' failure experiences and their related factors. Korean J Med Educ. 2012;24(3):233-240.

4. Bandura A. Social foundations of thought and action: a social cognitive theory. Englewood Cliffs, USA: PrenticeHall; 1986.

5. Lent RW, Brown SD, Hackett G. Contextual supports and barriers to career choice: a social cognitive analysis. J Couns Psychol. 2000;47(1):36-49.

6. Blustein DL. The role of goal instability and career self-efficacy in the career exploration process. J Vocat Behav. 1989;35(2):194-203.

7. Swanson JL, Daniels KK, Tokar DM. Assessing perceptions of career-related barriers: the Career Barriers Inventory. J Career Assess. 1996;4(2):219-244.

8. Swanson JL, Woitke MB. Theory into practice in career assessment for women: assessment and interventions regarding perceived career barriers. J Career Assess. 1997;5(4):443-462.

9. Kim EY. A study for the development and validation of 
the Korean college students' career barrier inventory. Korean J Couns Psychother. 2002;14(1):219-240.

10. Lee DH. Roles of career barriers in career decisionmaking: predicting variable or moderating variable. Korean J Couns. 201 1;12(1):59-80.

11. Lent RW, Brown SD, Talleyrand R, et al. Career choice barriers, supports, and coping strategies: college students' experiences. J Vocat Behav. 2002;60(1):61-72.

12. Lee EK. A study on the effect of self-efficacy upon the career development [dissertation]. Seoul, Korea: Ewha Womans University; 2001.

13. Kwon EK. The development and verification of a career group-counseling program based on social cognitive career theory for university students [dissertation]. Changwon, Korea: Kyungnam University; 2013.

14. An H, Kim E, Hwang J, Lee S. Analysis of medical students' needs for development of a career guidance program. Korean J Med Educ. 2014;26(3):209-216.

15. Hwang YK. A study on social-support perceived by adolescent peer-group and psychosocial maturity [master's thesis]. Seoul, Korea: Ewha Womans University; 1996.

16. Kim BH. Career decision level and career preparation behavior of the college students [dissertation]. Seoul, Korea: Seoul National University; 1997.

17. Seong TJ. Easy statistical analysis with SPSS/AMOS. 2nd ed. Seoul, Korea: Hakjisa; 2015.

18. Hong $\mathrm{S}$. The criteria for selecting appropriate fit indices in structural equation modeling and their rationales. Korean J Clin Psychol. 2000;19(1):161-177.

19. Sobel ME. Some new results on indirect effects and their standard errors in covariance structure models. Sociol Methodol. 1986;16:159-186.

20. You SB, Yoon HM. Effects of career barriers and social support on college students' career self-efficacy and preparation behavior. Korean J Fam Welf. 2014;19(3): 405-421.

21. Son EY, Son JH. The Korean college students' career decision and career preparation behavior from the perspective of social cognitive career theory. Korean J Couns Psychother. 2005;17(2):399-417.

22. Oh EJ. The mediation effect of career decision making self-efficacy in the relationship between career barriers perceived by undergraduates and career preparation behavior. Korean J Youth Stud. 2014;21:31-58. 